ISSN : 2087-2461

PENANGGUNG JAWAB Dekan FIKOM

Evie Sofiati MI, M.I.Kom

Sekretaris Dekan

Dian Marhaeni K, M.Si

Ketua Penyunting

Made Dwi Adnjani, M.Si

Sekretaris

Mubarok, M.Si

Bendahara

Parwati, SH

Dewan Penyunting

Trimanah, M.Si

Edi Ismoyo, M.Si

Suharyoso, S.Sos

Seksi Usaha

Endang Winarsih, S.Sos

Sirkulasi dan Distribusi

Aldino Leoniv, ST

Alamat Redaksi

Fakultas Ilmu Komunikasi

Universitas Islam

Sultan Agung Semarang

J1. Raya Kaligawe Km. 4

Po. Box 1054/SM

Semarang 50112

Telp. (024) 6583584

ext. $448 / 449$

Fax. (024) 6582455

email : jurnalfikom@yahoo.com
Pengaruh Perubahan Nama Terhadap Citra Pada Telkom

University

Felesia Ekafaya Kirianawati, Roro Retno Wulan,

Kharisma Nasionalita

felesiaekafay@gmail.com

Komunikasi Lintas Budaya Etnis India, Etnis China serta

Pribumi di kampung Lubuk Pakam

Meilani Dhamayanti

mdhamayanti73@gmail.com

Analisis Komunikasi Pemasaran Melalui Strategi Brand Activation Pond's Untuk Meraih Top Brand Award 2013 Rustono Farady Marta ${ }^{1}$, Pricillia ${ }^{2}$, Maria Fransisca Kosasih ${ }^{3}$, Maria Christina Evelyn Iskandar ${ }^{4}$

rustonofarady@gmail.com ${ }^{1}$, icil_22@hotmail.com ${ }^{2}$, s43_s43@yahoo.com ${ }^{3}$,

mariachristinaevelyne@gmail.com ${ }^{4}$

Analisis Isi Visual Iklan Dan Strategi Kreatif Kategori Print Ad Pemenang Gold, Silver, dan Bronze Citra Pariwara 2015

Dina Nur Handayani ${ }^{1}$ (dinurhdyn@gmail.com)

Ratih Hasanah Sudrajat ${ }^{2}$ (kumaharatih@gmail.com ${ }^{2)}$

Ayub Ilfandy Imran ${ }^{3}$ (a_ilfandy@yahoo.com ${ }^{3}$ )

Refleksi Citra Indonesia Sebagai Dampak Politik Migrasi TKI

ke Malaysia

Mutia Rahmi Pratiwi (mutiarahmipratiwi@gmail.com)

Amida Yusriana (amidayusriana88@gmail.com)

$46-59$

Karakteristik Press Release Praktisi Public Relations Hotel di Yogyakarta

Margaretha Sonya, Meylani Yo, Nobertus Ribut Santoso

margaretha_sonyalee@yahoo.com

$60-70$

Isu LGBT dalam Bingkai Media Online

Muhammad Ghifari Putra ${ }^{1}{ }^{1}$ ghifarigp@gmail.com)

Kharisma Nasionalita ${ }^{2}$

${ }^{2}$ nasionalita.kharisma@gmail.com

$71-87$

Telepon Selular dan Ruang Publik : Representasi Identitas Siswantini

yjuliman@gmail.com

$88-94$

Kepemilikan dan Bingkai Media (Analisis Framing Pemberitaan Joko Widodo Sebagai Kandidat Calon Presiden pada Koran SINDO)

Nani Kurniasaril (nani.kurniasari@kalbis.ac.id ${ }^{1}$ )

Gilang GustiAji² (gilangaji@unesa.ac.id²)

$96-116$ 


\title{
ANALISIS KOMUNIKASI PEMASARAN MELALUI STRATEGI BRAND ACTIVATION POND'S UNTUK MERAIH TOP BRAND AWARD 2013
}

\author{
Oleh : \\ Rustono Farady Marta \\ rustonofarady@gmail.com \\ Dosen Program Studi Ilmu Komunikasi - Universitas Bunda Mulia \\ Pricillia $^{1}$, Maria Fransisca Kosasih ${ }^{2}$, Maria Christina Evelyn Iskandar ${ }^{3}$ \\ 1iciL_22@hotmail.com, ${ }^{2}$ s43_s43@yahoo.com, ${ }^{3}$ mariachristinaevelyne @ gmail.com \\ Alumnus Program Studi Ilmu Komunikasi - Universitas Bunda Mulia
}

\begin{abstract}
TOP Brand Award is an annual prestigious reward for the best brands. On 4 March 2013, announced that POND'S has reached TOP Brand Award in category of face cleansing soap, moisturizer, whitening cream, face cleansing, and anti aging. A variety of strategies has been done to reach consumers accord with product types which formed in events, like "POND'S Make It Happen", "POND'S Teens Concert", and "POND'S Miracle Moment". The purpose of this research is to know about brand activation of POND'S that could reach consumers and relation between brand activation and success for TOP Brand Award 2013. Brand activation is an integration of communications by effective solutions for mobilizing consumers. This qualitative research uses literature study as data collecting method. The result of this study shows that POND'S brand activation was succeed if it looked from media value event parameter. Besides that, there is relation between brand activation and TOP Brand, because criterias of the winner are mind share, market share, and commitment share.
\end{abstract}

Keywords: brand activation, TOP Brand Award 2013, POND'S event.

\begin{abstract}
Abstrak
TOP Brand Award merupakan penghargaan tahunan yang prestisius untuk merek-merek terbaik. Pada tanggal 04 Maret 2013 merek POND’S diumumkan sebagai pemenang TOP Brand Award dalam kategori Sabun Pembersih Wajah, Pelembab Wajah, Krim Pemutih, Pembersih Wajah, Anti Aging. Berbagai aktivitas yang dilakukan mereka sesuaikan dengan kategori konsumen berdasarkan jenis produknya, seperti "POND'S Make It Happen”, "POND'S Teens Concert", dan "POND'S Miracle Moment". Penelitian ini ditujukan untuk mengetahui kegiatan brand activation yang dilakukan POND'S agar mampu menjangkau konsumen dan brand activation tersebut dikaitkan dengan keberhasilannya meraih TOP Brand Award 2013. Brand activation merupakan suatu kegiatan komunikasi yang terintergrasi sebagai solusi yang efektif untuk menggerakkan khalayak konsumen. Penelitian kualitatif ini menggunakan studi literature sebagai teknik pengumpulan data. Hasil dari studi ini menunjukkan bahwa kegiatan aktivasi merek POND'S telah berhasil bila ditinjau berdasarkan parameter media value event. Selain itu, hal menarik lainnya terdapat kaitan antara brand activation dengan TOP Brand, karena kriteria pemenang TOP Brand adalah mind share, market share, dan commitment share.
\end{abstract}

Kata kunci : Brand activation, Top Brand 2013, kegiatan POND’S 


\section{Pendahuluan}

Di tengah persaingan industri merek, setiap pencipta produk akan berjuang keras untuk menaikkan ketenaran mereknya. Mereka berusaha menjalankan berbagai strategi untuk meraih kesuksesan bagi citra korporasinya. Apresiasi terhadap merek juga merupakan salah satu aspek penting sebagai tolok ukur eksistensi kesuksesan dalam suatu merek perusahaan. TOP Brand Award merupakan salah satu penghargaan bergengsi untuk berbagai merek terbaik yang diadakan setiap tahunnya. Tidak bisa dipungkiri bahwa pemenang TOP Brand Award merupakan merek yang berkualitas dan kredibel di mata konsumen.

Pada tanggal 4 Maret 2013, telah diumumkan POND'S sukses meraih kemenangan sebagai TOP Brand Award 2013 untuk kategori "Sabun Pembersih Wajah dengan persentase $34,9 \%$, Pelembab Wajah dengan persentase 48,6\%, Krim Pemutih dengan memperoleh 48,8\%, Pembersih Wajah dengan persentase $34,5 \%$, dan Anti Aging dengan persentase $42,5 \%$ ".

\section{TOP Brand Award 2013}

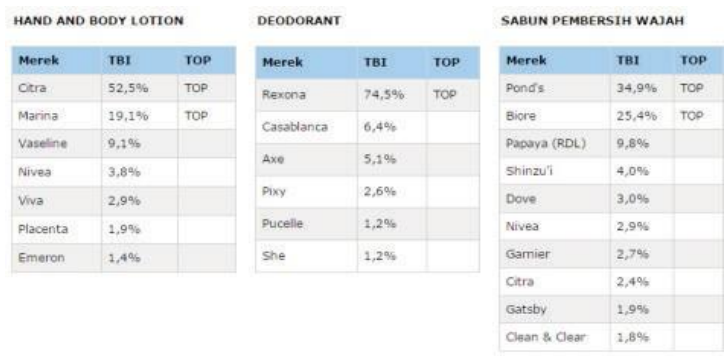

Gambar 1. POND'S meraih TOP Brand Award dalam kategori Sabun Pembersih Wajah

Berbagai kategori penghargaan yang berhasil diraih oleh POND'S merupakan bukti merek tersebut menjadi salah satu brand tersukses di Indonesia. Memang tidak bisa dipungkiri bahwa kesuksesan sebagai pemenang TOP Brand Award 2013 menunjukkan POND'S sebagai produk yang berkualitas dan terpercaya, namun kesuksesan yang diterima oleh POND'S merupakan salah satu hasil dari usaha POND'S dalam menjalankan berbagai upaya komunikasi pemasaran yang diterapkan, salah satunya melalui strategi brand activation.

Berbagai strategi dilakukan oleh POND'S untuk menyentuh setiap kalangan konsumen sesuai dengan jenis produknya, yang diwujudkan dalam berbagai aktivitas. Sebut saja "POND'S Make It Happen" merupakan kegiatan yang diperuntukkan untuk dewasa muda dan remaja, "POND'S Teens Concert” yang memiliki target remaja, "POND'S Miracle Moment" untuk kalangan usia 28-30 tahun bersama suami, serta aktivitas lainnya yang diselenggarakan oleh POND'S.

Melihat berbagai aktivitas tersebut, penulis tertarik untuk menganalisis brand activation yang dilakukan berdasarkan parameter media value event guna mengetahui keterkaitan aktivitas yang dilakukan POND'S yang dilakukan selama tahun 2012 dengan kesuksesan meraih Top Brand Award 2013.

Berdasarkan latar belakang di atas, maka permasalahan yang diangkat dalam penelitian ini adalah sebagai berikut:

1. Apa saja kegiatan brand activation yang dilakukan oleh POND'S, sehingga mampu menyentuh setiap kalangankonsumennya?

2. Bagaimana kaitan kegiatan brand activation yang dilakukan oleh POND'S dengan keberhasilannya meraih TOP Brand Award 2013?

Merek unggulan Indonesia adalah merek yang dirumuskan oleh Frontier Consulting Group berdasarkan mind share, market share, dan commitment share. Mind share mengindikasikan kekuatan merek di dalam benak konsumen kategori produk bersangkutan. Market share menunjukkan kekuatan merek di dalam pasar tertentu dalam hal perilaku pembelian aktual dari konsumen. Commitment share menjelaskan kekuatan merek dalam mendorong konsumen untuk membeli merek terkait di masa mendatang.

Untuk mendapatkan merek Top Indo- 
nesia, digunakan dua kriteria, yaitu merekmerek yang memperoleh indeks minimum merek top dan merek-merek yang berada dalam tiga besar pada masing-masing kategori (Suyanto, $2007: 1$ ).

Menurut M. Suyanto dalam bukunya Marketing Strategy Top Brand Indonesia, mendefinisikan merek sebagai sebuah kombinasi dari nama, kata, simbol, atau desain yang memberi identitas produk. Merek mempunyai peran ekonomi jika merek tersebut diproduksi secara massal sehingga mencapai skala ekonomis dan merek yang sukses dapat menghambat bagi pesaing yang ingin memperkenalkan merek yang sama. Merek juga mempunyai peran strategis dengan menjadi pembeda antara merek yang ditawarkan perusahaan dengan merek para pesaingnya.

Dari perspektif konsumen, merek yang terpercaya merupakan jaminan atas konsistensi kinerja suatu produk dan menyediakan manfaat yang dicari konsumen ketika membeli produk atau merek tertentu. Merek juga merupakan janji kepada konsumen bahwa dengan hanya menyebut namanya, timbul harapan bahwa merek tersebut akan memberikan kualitas terbaik, kenyamanan, status dan pertimbangan lain ketika konsumen melakukan pembelian.

Merek terdiri dari merek privat (private brand/store brand/distributor brand/ private label), merek spesifik atau individual (spesific/individual brand), merek lini/keluarga (line/familuy brand), merek perusahaan (corporate brand), merek kombinasi (combination brand). Merek spesifik merupakan strategi untuk memberikan nama merek pada sebuah produk spesifik. Unilever menggunakan strategi ini, misalnya Axe untuk merek deodoran, Blue Band untuk margarin, Domestos untuk obat nyamuk, Pepsodent untuk pasta gigi dan Sunsilk untuk sampo (Suyanto, 2007 : 77-78).

Menurut kutipan dari skripsi Sindhunatan dan Senjaya yang berjudul "Creative Implementation Hipsta.co.id", brand activation adalah salah satu bentuk promosi merek yang mendekatkan dan interaksi merek dengan penggunanya melalui aktivitas pertandingan olahraga, hiburan, kebudayaan, sosial, atau aktivitas publik yang menarik perhatian lainnya.

Dalam konsep Connected Marketing seperti yang dikemukakan Paul Marsden (2013), event atau brand activation merupakan salah satu cara dalam menciptakan buzz. marketing atau pembicaraan (word of mouth) yang positif tentang perusahaan, produk atau jasa oleh media dan publik.

Para pemasar menggunakan brand activation atau event marketing untuk membina hubungan dengan para konsumen, meningkatkan ekuitas merek, dan memperkuat ikatan dengan dunia perdagangan. Dengan kata lain, keberhasilan brand activation sangat tergantung pada kesesuaian antara merek, event, dan pasar sasaran. Karena itu, sebagaimana halnya dengan setiap keputusan komunikasi pemasaran lainnya, titik awal brand activation yang efektif adalah menentukan pasar sasaran dan menjelaskan tujuan yang akan dicapai oleh suatu event. Event pemasaran tidak akan bernilai, kecuali mencapai tujuan dari event tersebut.

Menurut Alberts (1997) yang dikutip dari Sindhunatan dan Senjaya dalam Skripsi yang berjudul "Creative Implementation Hipsta.co.id", brand activation adalah integrasi semua komunikasi melalui cara yang efektif dalam rangka menggerakkan konsumen. Activation berarti menstimulasi interest, trial, and loyalty. Menurutnya "brand activation is deliver the proof", artinya brand activation berfungsi menunjukkan bukti kepada konsumen.

Menurut Hermawan Kertajaya (2009), pada bukunya "MarkPlus Strategy: New Wave Marketing", mengungkapkan bahwa ada dua macam cara untuk menjaga konsistensi brand, yaitu melalui Brand Visualization dan Brand Activation.

Brand visualization adalah suatu bentuk komunikasi merek melalui bentuk visualisasi, sehingga mudah dipahami dan diingat pelanggan secara cepat. Brand visualization termasuk dalam komunikasi brand 

Activation Pond's Untuk Meraih Top Brand Award 2013

satu arah (one way marketing), contohnya adalah advertising. Di sisi lain brand activation adalah suatu bentuk promosi brand yang dapat mendekatkan konsumen dengan brand tersebut, serta menimbulkan interaksi antara brand dengan konsumen dalam suatu kegiatan tertentu. Brand activation ini termasuk dalam komunikasi brand dua arah (two way marketing).

Kekuatan dari brand activation adalah:

1. Menyampaikan pesan komunikasi secara langsung.

2. Pengenalan dan pemahaman brand.

3. Menciptakan komunikasi dua arah.

4. Memberikan experience bagi konsumen.

5. Menciptakan penjualan.

6. Meningkatkan loyalitas.

7. Dapat diukur.

Menurut majalah MIX edisi Agustus 2009, parameter keberhasilan brand activation adalah:

\section{Cost per head}

Hal ini didasarkan pada berapa jangkauan audience yang dapat dicapai dengan brand activation. Semakin banyak jangkauannya, artinya brand activation tersebut semakin efektif dan semakin baik. Jangkauan di sini tidak harus berarti produk sampling atau produk experience tetapi sekedar informasi mengenai brand activation dan tahu informasi mengenai perusahaan penyelenggara. Ini biasa dilakukan oleh perusahaan consumer goods.

2. Sales target

Ini adalah metode yang paling banyak digunakan oleh perusahaan tradisional, brand activation selalu dikaitkan dengan target penjualan produk. Yang utama di sini adalah pencapaian volume sesuai target awal.

\section{Brand switch}

Hampir sama dengan sales target tetapi yang diutamakan adalah seberapa audience melakukan brand switch dari brand competitor sebelumnya.

\section{Media value event}

Berdasarkan berapa banyak tulisan atau editorial yang didapatkan dari temanteman media. Semakin banyak tulisan positif yang didapat tentunya akan semakin efektif. Biasanya formula yang digunakan adalah dengan menggunakan advertising value equivalent ( $A V E)$.

Brand activation bukanlah sebuah teori melainkan sebuah langkah alami dalam evolusi merek. Dalam suatu penelitian yang dibuat oleh Paul Morel, Peter Preisler, dan Anders Nyström (2002) sebagai brand strategist agensi desain Starsky, melihat kemungkinan yang lebih dalam dari suatu merek, dengan strategi dan posisi untuk menemukan suatu aset yang lebih relevan, mampu beradaptasi dan menguntungkan bagi seluruh perusahaan. Para peneliti telah mengumpulkan pengalaman dan pengetahuan mengenai lingkungan merek saat ini baik di dalam maupun di luar perusahaan. Brand activation adalah sebuah ekspresi dari bagaimana pendekatan merek menajemen melalui sebuah organisasi.

Mereka percaya bahwa ketika semua strategi merek yang diperlukan dilaksanakan, perusahaan hanya perlu mengeksekusinya ke seluruh organisasi dan konsumen. Suatu merek dapat menjadi aktif dalam situasi apapun, yang dapat diringkas menjadi empat (4) bagian; produk dan layanan, karyawan, identitas, dan komunikasi.

Brand activation juga mengkomunikasikan posisi melalui iklan. Pada dasarnya brand activation berkontribusi dalam menciptakan kepercayaan antara pelanggan, masyarakat dan merek. Kepercayaan adalah salah satu kunci dalam dalam membentuk kesetiaan antara pelanggan dan merek. Pada akhirnya, perusahaan dapat menggunakan kesetiaan untuk membentuk perilaku pembelian kembali atau suatu rekomendasi pelanggan. Cukup penting untuk disebutkan bahwa ketika perusahaan 
bergantung pada kesetiaan pelanggan untuk memperluas; tantangan utamanya adalah untuk selalu mempertahankan hubungan kepercayaan yang ada antara pelanggan dan merek.

Menurut Terence A. Shimp dalam Buku Periklanan Promosi mendefinisikan brand activation sebagai suatu bentuk promosi merek yang mendekatkan dan membangun interaksi merek dengan penggunanya melalui berbagai jenis aktivitas, seperti contohnya: pertandingan olahraga, hiburan, kebudayaan, sosial, atau aktivitas publik yang menarik perhatian lainnya. (Shimp, 2003)

Dampak kegiatan brand activation diuraikan oleh Pudjiastuti (2010), dimana terdapat beberapa aspek yang efektif dalam mempengaruhi masyarakat sebagai sasarannya, yaitu: (1) aspek kognitif, dimana brand activation dapat mempengaruhi awareness dan pengetahuan masyarakat terhadap perusahaan, brand, atau produk yang ditawarkan; (2) aspek afektif, dimana brand activation dapat digunakan untuk mengatasi kesalahpahaman dan prasangka serta membantu mengkomunikasikan pesan dari brand terhadap konsumen; dan (3) aspek konatif, dimana brand activation dapat mempertahankan penerimaan masyarakat akan produk, brand, atau perusahaan, atau dengan kata lain dapat mempertahankan loyalitas konsumen.

Intinya, branding lebih dari sebuah iklan. Saatnya bagi perusahaan-perusahaan untuk meningkatkan aset mereka di seluruh organisasi. Masyarakat postmodern menuntut agar merek memenuhi janji-janji mereka ke dalam setiap interaksi baik itu melalui produk dan layanan, karyawan, identitas atau komunikasi. Suatu merek yang koheren dalam empat bagian ini akan meraih kepercayaan dan kesetiaan antara hubungan pelanggan yang menguntungkan dengan merek serta orang-orang.

\section{Metode Penelitian}

Metode adalah cara atau strategi menyeluruh untuk menemukan atau memperoleh data yang diperlukan. (Soehartono, 2011: 9).
Metodologi dipengaruhi atau berdasarkan perspektif teoretis yang kita gunakan untuk melakukan penelitian, metodologi juga diukur berdasarkan kemanfaatannya, dan tidak bisa dinilai apakah suatu metode benar atau salah. Untuk menelaah hasil penelitian secara benar, tidak cukup sekadar melihat apa yang ditemukan peneliti, tetapi juga bagaimana peneliti sampai pada temuannya berdasarkan kelebihan dan keterbatasan metode yang digunakannya. Adapun pengertian dari metode penelitian adalah teknik-teknik spesifik dalam penelitian (Mulyana, 2001:146).

Metode yang digunakan terkait penelitian ini adalah pendekatan kualitatif dengan pengumpulan literatur. Mengingat judul penelitian ini mengangkat topik mengenai brand activation yang dilakukan oleh POND'S. Dalam riset ini, penulis hanya mempelajari dokumen yang telah diterbitkan melalui berbagai media mengenai topik permasalahan yang memuat informasi, gagasan, data, dan bukti yang ditulis berdasarkan sudut pandang tertentu.

Penulis mengumpulkan data-data yang tepat dalam menyusun penelitian tersebut. Media website POND'S dan juga beberapa media jejaring sosial seperti Facebook dan Twitter milik POND'S yang merupakan sumber utama dan pendukung bagi peneliti untuk memperoleh informasi serta data-data penting yang dibutuhkan.

Studi literatur berisikan tentang uraian teori dan bahan yang dijadikan acuan sebagai landasan penelitian, sehingga lewat uraian tersebut peneliti dapat mengetahui bagaimana brand activation yang dilakukan POND'S melalui sumber-sumber yang faktual. Peneliti memperhatikan pada setiap kegiatan-kegiatan yang dilakukan POND'S dalam menjalankan brand activation itu sendiri.

\section{Hasil dan Pembahasan}

Hasil penelitian ini adalah adanya keterkaitan antara brand activation yang dilakukan POND'S dengan kesuksesan yang diraihnya saat ini. Tentunya, kualitas produk 
POND'S tidak perlu dipertanyakan mengingat salah satu produk Unilever yakni perusahaan besar yang sudah mendunia.

POND'S merupakan sebuah produk dalam kategori personal care di bawah naungan PT. Unilever Indonesia Tbk. Produk POND'S pertama diproduksi pada tahun 1846, sejak saat itu merek tersebut telah menjadi produk kelima perawatan diri yang paling menguntungkan di seluruh dunia. Pada tahun 1886, POND'S diluncurkan kembali sebagai POND'S Extract dan pada tahun 1914 POND'S Cold Cream dan Vanishing Cream menandai evolusi merek menjadi lambang (ikon) kecantikan. Pada pertengahan tahun 1920-an, POND'S mencerminkan penguasaan posisi pasar ini dengan pengesahan dari ratu, bintang Hollywood, dan masyarakat pemerhati masalah kecantikan. Citra gayanya didukung oleh jaminan penyampaian produk dan pengertian rutinitas dan kebutuhan kecantikan wanita.

Dalam kajian teori, sudah dipaparkan bahwa brand activation adalah suatu bentuk promosi brand yang dapat mendekatkan konsumen dengan brand tersebut, serta menimbulkan interaksi antara brand dengan konsumen dalam suatu kegiatan tertentu. Brand activation adalah integrasi semua komunikasi melalui cara yang efektif dalam rangka menggerakan konsumen. Brand activation ini termasuk dalam komunikasi brand dua arah (two way marketing). Dalam penelitian ini, penulis menggunakan parameter keberhasilan brand activation yaitu media value event. Beberapa aktivitas atau event yang diselenggarakan oleh POND'S pada tahun 2012, akan dibahas oleh penulis antara lain sebagai berikut:

1. POND'S Teens Concert. Pada tahun 2012, POND'S menggelar konser Jessie J pada hari Minggu, 18 Maret di JiExpo Kemayoran Hall D2 di Jakarta.
Analisis Komunikasi Pemasaran Melalui Strategi Brand Activation Pond's Untuk Meraih Top Brand Award 2013

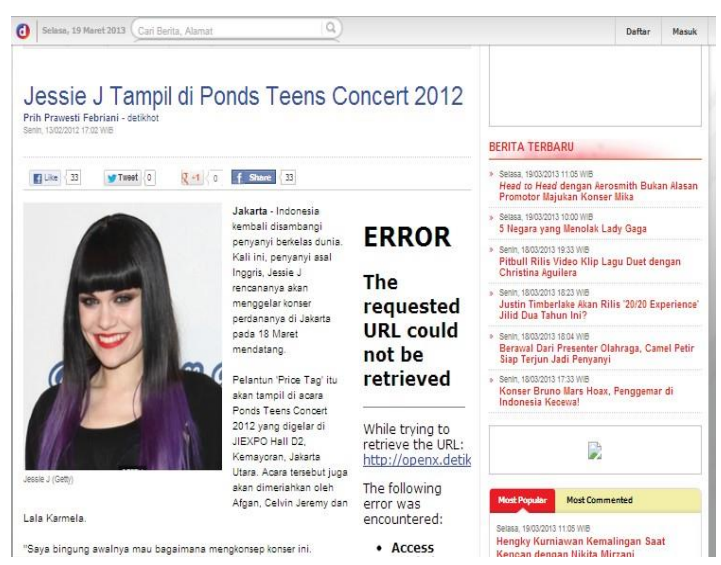

Gambar 2. POND'S Teen Concert Jessie J (Sumber: www.detik.com)

Voucher dapat dibeli tanggal 6 Februari-17 Maret 2012. Cara untuk memperoleh tiket konser ini adalah melakukan pembayaran terhadap paket POND'S seharga tiga ratus lima puluh ribu rupiah melalui Raja Karcis, POND'S Institute, dan Indomaret. Segmentasi dari kegiatan ini adalah kalangan menengah ke atas dan targetnya adalah remaja.

2. POND'S Make It Happen, merupakan kegiatan yang dapat membantu konsumennya untuk lebih dekat dengan mimpinya. Ditujukan bagi usia pelajar dan mahasiswa, yakni rentang 13-25 tahun membentuk grup yang disebut "gank" beranggotakan 3-5 orang. Berbagai artis dirangkul untuk menjadi icon dalam kegiatan ini, yaitu Pevita Pearce, Olivia Jensen, Sonia Eryka, Lala Karmela, Calvin Jeremy, Peewee Gaskins, dan Afgan.

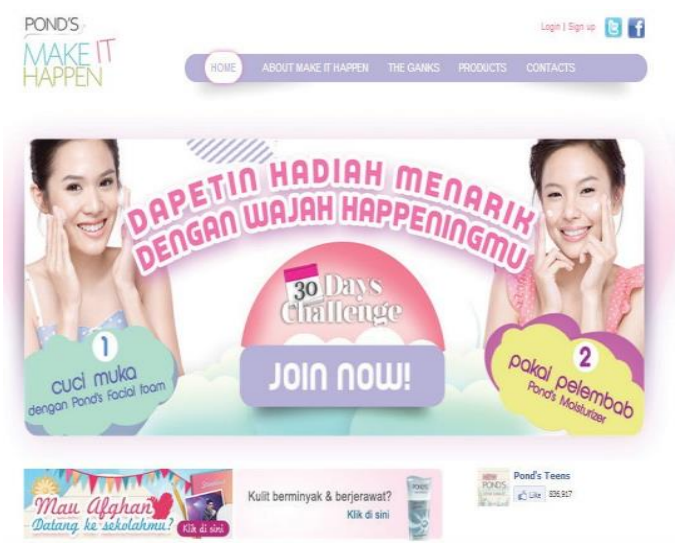

Gambar 3. POND'S Make It Happen (Sumber: www.pondsmakeithappen. com) 
3. POND'S Miracle Moment, dimana target pesertanya adalah wanita yang sudah menikah. Mereka menuliskan cerita maksimal 500 kata tentang kisah romantis dengan pasangan pada dinding halaman Fan Page "POND'S Indonesia". Pemenangnya akan mendapatkan perjalanan "Bulan Madu Kedua" ke Paris termasuk uang saku yang akan disediakan oleh pihak penyelenggara.

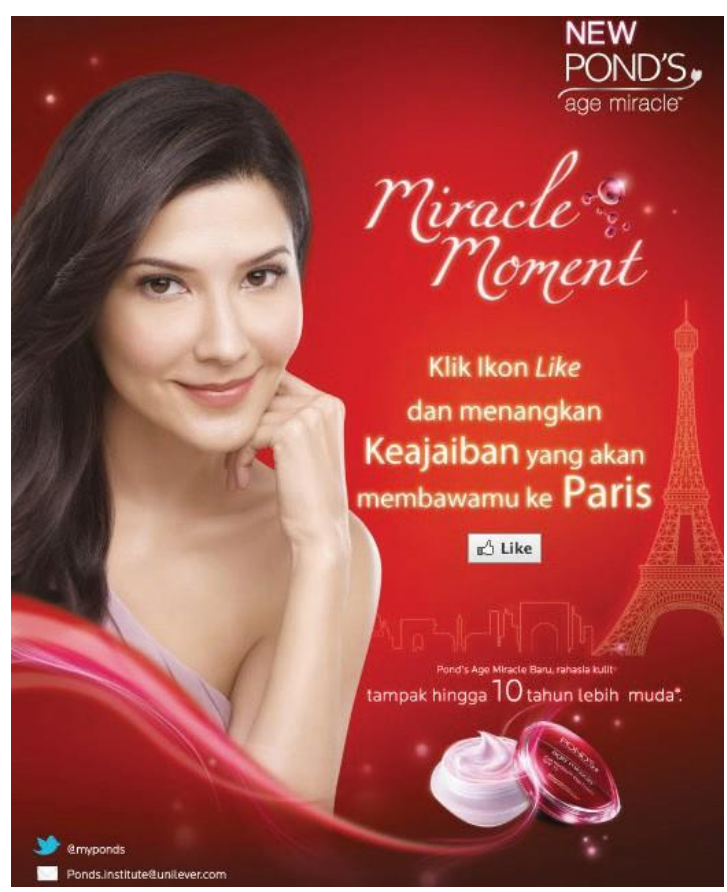

\section{Gambar 4. POND'S Miracle Moment (Sumber: www.facebook.com)}

Melalui berbagai kegiatan yang dilakukan oleh POND'S, membuat merek ini semakin dekat dengan konsumen. POND'S menyadari bahwa target konsumennya cukup beragam, sehingga perlu dilakukan beberapa aktivitas yang berbeda untuk menyentuh konsumen. Kegiatan yang diselenggarakan berhasil menarik banyak peminat dan tentunya disesuaikan dengan target konsumennya. Sebagai contoh, POND'S Teens Concert disesuaikan dengan artis Jessie J yang banyak disukai oleh kalangan remaja.

POND'S Miracle Moment memberikan hadiah bulan madu dan dapat dilihat berhasil menarik wanita untuk berpartisipasi dalam kegiatan ini. Kegiatan ini mengacu kepada brand loyalty. Selain itu, publikasi kegiatan ini juga dapat dikatakan cukup intens, baik melalui jejaring sosial, majalah, youtube, maupun iklan televisi.

Menurut penulis, aktivitas yang dilakukan oleh POND'S cukup berhasil menarik perhatian konsumen dan media. Hal tersebut dapat kita lihat dari berbagai tulisan positif yang diberikan oleh media, terutama media internet (new media). Beberapa blog juga turut memberitakan kegiatan yang diselenggarakan oleh POND'S dan memberikan respon positif dalam menanggapi kegiatan tersebut.

Terdapat kaitan antara brand activation yang dilakukan dengan kesuksesan TOP Brand Award 2013 yang diraih oleh POND'S. Kriteria kemenangan TOP Brand ditinjau berdasarkan mind share, market share, dan commitment share. Mind share yang berhasil dibangun oleh POND'S adalah kekuatan merek POND'S dalam benak konsumen karena intensitas publikasi produk dan kegiatan yang dilakukan. Market Share yang berhasil dibangun adalah kekuatan merek dalam pasar tertentu melalui perilaku pembelian konsumen. Hal tersebut dapat ditinjau dari tingkat pembelian dari setiap rangkaian produk POND'S. Commitment Share menjelaskan bahwa melalui brand activation dapat meningkatkan kekuatan merek dalam mendorong konsumen untuk membeli merek POND'S di masa mendatang.

Hal ini senada dengan pernyataan yang dikemukakan oleh Denny Siregar (2011), selaku Ketua Pengembangan Brand Activation PPPI Pusat sekaligus Business Strategy Director RAPP (PT. Riau Asia Pulp \& Paper). Ia mengungkapkan bahwa brand activation merupakan suatu kegiatan pemasaran yang dilakukan untuk menarik hati konsumen dengan berbagai saluran komunikasi yang terintegrasi, seperti TV, radio, cetak, internet, event, Short Message Service (SMS), social media, dan sebagainya.

Adapun kegiatan POND's Teens Concert dengan mengundang Jesssie J. di tahun 2012 memperoleh gaung yang cukup besar melalui sosialisasi yang diletakkan pada website unilever sebagai berikut: 


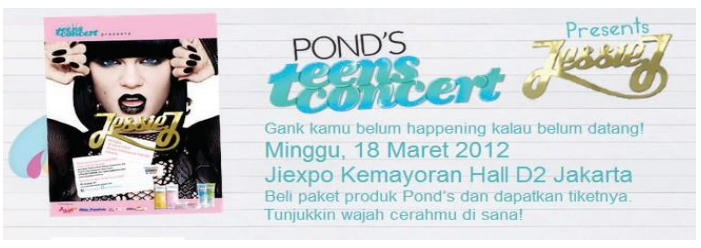

Gambar 5. POND's Teens Concert (Sumber: www.unilever.co.id)

Salah satu media yang dimanfaatkan sebagai bentuk sosialisasi POND's Miracle Moment ialah bekerjasama dengan 97,9 Female Radio mengadakan talkshow sebagaimana gambar berikut:

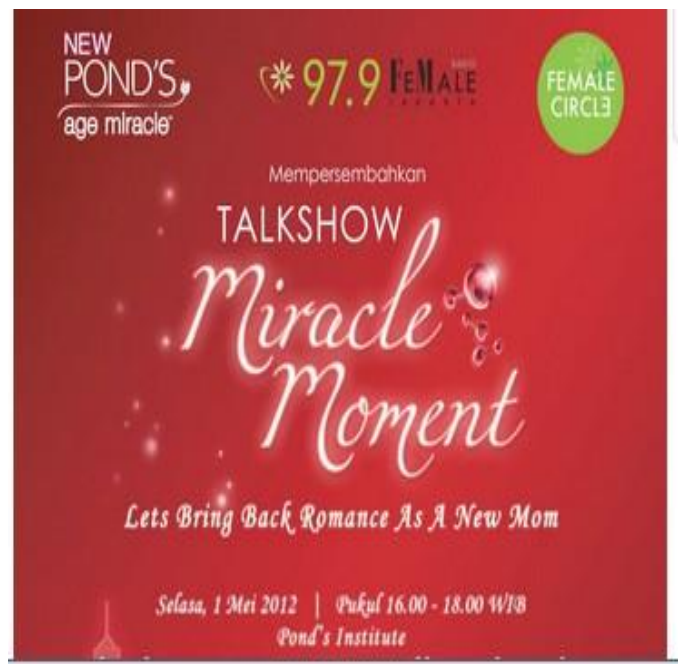

Gambar 6. Talkshow Miracle Moment (Sumber: twitter.com/979femaleradio)

Berbagai usaha tersebut dilakukan untuk mengubah perilaku konsumen dalam mempertahankan loyalitas konsumen terhadap suatu brand dan membantu produk tersebut dalam memperluas pasar. Brand activation mengandung pesan komunikasi untuk take to action ataupun pesan komunikasi yang bersifat call to action message.

Kegiatan brand activation ialah bagian dari komunikasi atau interaksi pemasaran yang terintegrasi (Integrated Marketing Ccommunication) antara brand dan konsumennya yang dibalut dengan konsep kreatif yang bertujuan agar brand dapat selalu dekat dengan konsumennya.

\section{Penutup}

Berdasarkan hasil penelitian di atas, peneliti menarik kesimpulan bahwa brand activation merupakan hal yang penting karena dapat membina hubungan dengan para konsumen, meningkatkan ekuitas merek, dan memperkuat ikatan dengan dunia perdagangan. Dengan kata lain, keberhasilan brand activation sangat tergantung pada kesesuaian antara merek, event, dan pasar sasaran. Begitu pula POND'S yang mencapai kesuksesan melalui brand activation yang dilakukan berhasil mencapai kesuksesannya. Menurut penulis, brand activation yang dilakukan POND'S cukup sukses jika ditinjau dari parameter brand activation yaitu media value event.

Selain itu, terdapat kaitan antara brand activation dengan TOP Brand, karena kriteria pemenang TOP Brand adalah mind share, market share, dan commitment share. POND'S berhasil memenuhi tiga kriteria di atas, sehingga POND'S mampu menjadi pemenang TOP Brand Award dalam beberapa kategori.

Mengingat brand activation itu penting dalam menjalin hubungan dengan konsumen, maka penulis mengajukan saran sebagai berikut:

Agar POND'S dapat mengembangkan aktivitas yang dilakukan agar mampu menjalin hubungan yang lebih dekat dengan konsumen setia POND'S;

Dari sisi publikasi, diharapkan agar POND'S meningkatkan intensitas iklan baik dalam bentuk produk maupun berbagai aktivitasnya, maka apat tersebar secara lebih merata;

Strategi yang dilakukan POND'S harus dipertahankan mengingat prestasi yang telah dicapai, namun penulis menyarankan agar dilakukan pengembangan berkelanjutan, agar mencapai prestasi yang lebih baik. 


\section{Daftar Pustaka}

Chaney, P. \& Marsden, P. (2013), The social commerce handbook: 20 secrets for turning social media into social sales, New York: McGraw-Hill.

Kartajaya, Hermawan. (2009). Markplus on Strategy: New Wave Marketing. Jakarta: Gramedia Pustaka Utama.

Morel, Paul, Peter Preisler dan Anders Nyström. (2002). Brand Activation. Stockholm: Starsky Insight.

Mulyana, Deddy. (2001). Metodologi Penelitian Kualitatif : Paradigma Baru Ilmu Komunikasi dan Ilmu Sosial Lainnya. Bandung: Remaja Rosda Karya.

Pudjiastuti, Wahyuni. (2010). Special Event. Jakarta: Elex Media Komputindo

Shimp, Terence. (2003). Periklanan Promosi: Aspek Tambahan Komunikasi Pemasaran Terpadu, Jakarta: Erlangga

Sindhunatan, Raymond dan Ivan Senjaya. (2012). Creative Implementation Hipsta. co.id. Surabaya : Universitas Kristen Petra.

Soehartono, Irawan, (2011). Metode Penelitian Sosial: Suatu Teknik Penelitian Bidang Kesejahteraan Sosial dan Ilmu Sosial lainnya, Bandung: Remaja Rosadakarya.

Suyanto, M.. (2007). Strategy Marketing Top Brand Indonesia. Yogyakarta : Andi Publisher.
Analisis Komunikasi Pemasaran Melalui Strategi Brand Activation Pond's Untuk Meraih Top Brand Award 2013

\section{Sumber Internet :}

http://www.topbrand-award.com/top- brandsurvey/survey-result/top-brand- index2013/ diakses tanggal 15 Maret 2013, pukul 18.44

http:// www. unilever. co.id/id/brands/ personalcarebrands/ponds/index.aspx diakses tanggal 16 Maret 2013, pukul 19.27

ht tp:// pondsm akeithappen.com/ syaratdanketentuan diakses tanggal 16 Maret 2013, pukul 19.30

http://www.empieee.net/2012/02/pondsmake-it-happen.html diakses tanggal 16 Maret 2013, pukul 19.35

http://www.facebook.com/note.php?note $\mathrm{id}=346904832014529$ diakses tanggal 16 Maret 2013, pukul 19.38

http://hot.detik.com/music/read/2012/02/13/ 170204/1841303/228/jessie-j-tampil-diponds-teens-concert-2012 diakses tanggal 16 Maret 2013, pukul 17.42

https://twitter.com/979femaleradio diakses tanggal 16 Maret 2013, pukul 17.52

http://www.p3i-pusat.com/berita/214-out-ofhome-dan-brand-activation diakses pada 16 Maret 2013, pukul 17.16 